\title{
Tires: unstable materials for artificial reef construction
}

\author{
R. L. Sherman \& R. E. Spieler \\ Farquhar College of Arts and Sciences and Oceanographic Center, \\ Nova Southeastern University, USA
}

\begin{abstract}
Artificial reefs of varied materials have been deployed worldwide to acquire large and diverse fish assemblages for both commercial and sport fishers, and SCUBA divers. Beginning in 1967, environmental resource managers and local fishers initiated a project to build an artificial reef using banded, but unballasted, waste automobile and truck tires offshore Broward County, Florida, USA. Estimates of the number of tires placed offshore range between $1,000,000$ $2,000,000$. Since deployment, storm events and ocean currents have caused the bands to give way and the break-up of the reef. Over the years, many tires have washed ashore onto recreational beach areas. Tires that remain in the water continue to move with wave action and currents. Many of these remaining tires have already been forced up against the offshore edge of natural reef with numbers at individual sites estimated in the 100,000's. The objectives of this project were to examine the feasibility of removing the tires as well as gain subjective insight into the impact of the tires on natural habitat. Sixteen hundred tires were removed from the reef edge and recycled. The potential problems arising from the use of tires in artificial reef construction were apparent. Natural reef fauna was broken and buried providing a seascape resembling a junkyard. The shortsighted use of unstable material to construct artificial reefs is an issue facing many coastal areas. Disturbance of this unstable material has futher added to other natural and anthropogenic stresses suffered by the coral reef systems and the wildlife they support. Clearly, unstable materials, such as tires, are not suitable for artificial reef construction. If already deployed, tires should be removed to prevent physical damage to the natural habitat and reduce the related negative biological impacts, in turn, limiting economic loss to local communities benefiting from use of the natural reef.
\end{abstract}

Keywords: southeast Florida, recycling, habitat restoration. 


\section{Introduction}

When individuals or localities first constructed and deployed artificial reefs, they were intended to act as fish aggregating devices. For most of the history of artificial reefs little critical thought was given to the materials used. Often, the reefs were, and still are, 'constructed' using materials of opportunity such as construction debris, oil-drilling towers, automobiles, airplanes, or by sinking derelict ships. Once in place, the reefs generally develop large, diverse fish and invertebrate assemblages and are popular fishing and scuba diving sites.

As interest in artificial reef design and function increased, efforts were made to deploy reef materials with specific design criteria and planned functions [1, 2, 3]. Recent studies have examined material stability and biological interactions with different reef materials. Specially designed artificial reefs include concrete modules intended to test hypotheses about fish or invertebrate recruitment and the effects of predation on recruit survival [4-10]. These modules may also simply increase substrate complexity for recruitment by mimicking specific substrate types such as ledges and crevices that create refuge for juvenile fish and cryptic species $[6,10]$. Additional studies have been conducted examining the effects of site selection or water depth on fish or invertebrate assemblage formations $[7,8]$. These studies are commonly done with using pre-fabricated concrete artificial reef modules

However, not all potential artificial reef materials are created equal and some of the earlier artificial reef projects deployed materials unsuitable or poorly constructed for the marine environment. Beginning in 1967, a project was initiated to build an artificial reef offshore Broward County, Florida, USA in approximately $20 \mathrm{~m}$ water depth. The construction materials of choice were used car and truck tires. Tires are not readily broken down in the marine environment and also posed a difficult disposal problem for solid waste managers given already crowded land fill areas. Thus, their use as artificial reef construction material appeared an excellent solution to creating fish habitat while simultaneously providing an ecologically amenable solution to their disposal. Used tires were bundled in groups of eight and bound with strapping designed not to rust or corrode [11]. Raymond [12] reported that by the end of 1973 over a million tires had been deployed within a permitted area (fig. 1, 2). Other estimates range as high as two million [11]. The project was named the 'Osborn Tire Reef.'

The deployment was presumably designed with a two-fold purpose. The first was to increase substrate complexity in a flat, sandy area off the coast of southeast Florida for the purpose of creating habitat for fish most desired by local commercial and sport fishers, including snappers (Family: Lutjanidae), groupers (Serranidae), and jacks (Carangidae). The second, perhaps less obvious purpose, was to find a way to 'constructively' dispose of excess solid waste by using that waste as an inexpensive artificial reef material.

The near shore waters along the south east coast of Florida comprise a highly dynamic area with three coral reef tracts running north/south in sequentially deeper water. The coast is often exposed to multiple tropical storm events, 
including hurricanes, annually. During these tropical weather events wave action easily interacts with the substrate at the 20-meter depth. Over the past 25 years the constant dynamic interactions and stresses created by ocean currents and wave action have torn apart the Osborn Tire Reef and scattered most, if not all, of the tires over an area of approximately 300 x 500 meters.

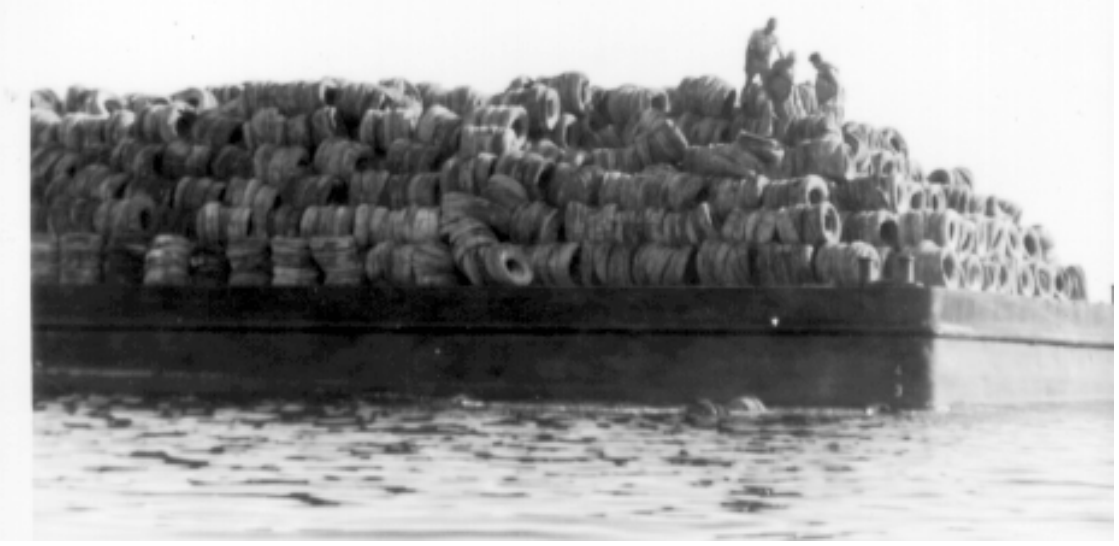

Figure 1: Tires bundled on barge in preparation for deployment, 1967. (Photograph courtesy of the Broward County Department of Planning and Environmental Protection.)

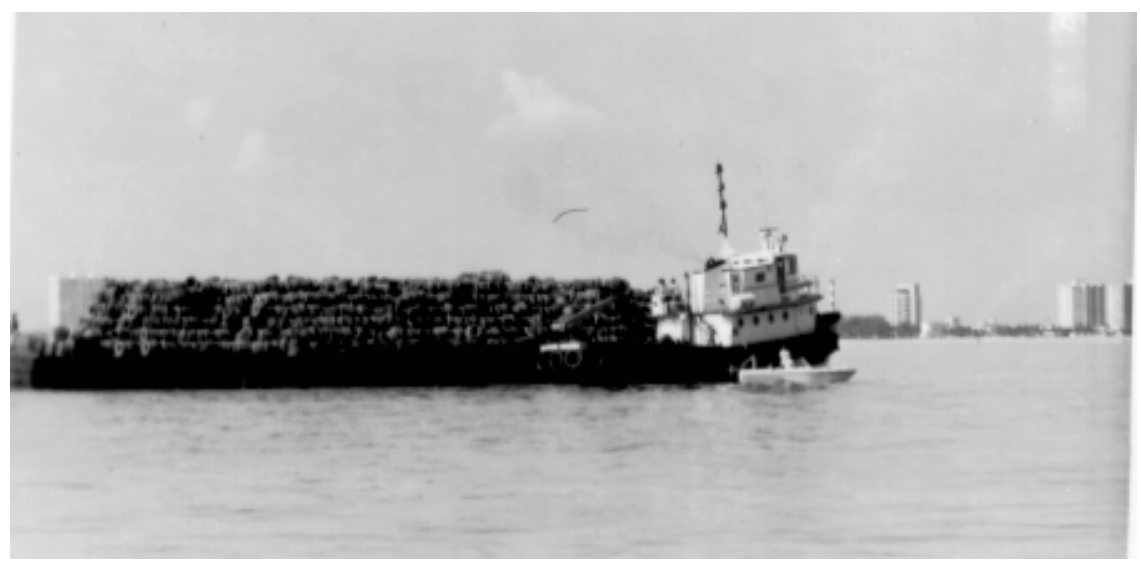

Figure 2: Barge of tires for artificial reef deployment, 1967. (Photograph courtesy of the Broward County Department of Planning and Environmental Protection.) 
Subsequent storms have deposited many individual tires from this field onto the beaches of Broward and neighboring counties. Those tires that have not washed up on the beaches are now scattered over this, approximately, $150,000 \mathrm{~m}^{2}$ landscape (fig. 3).

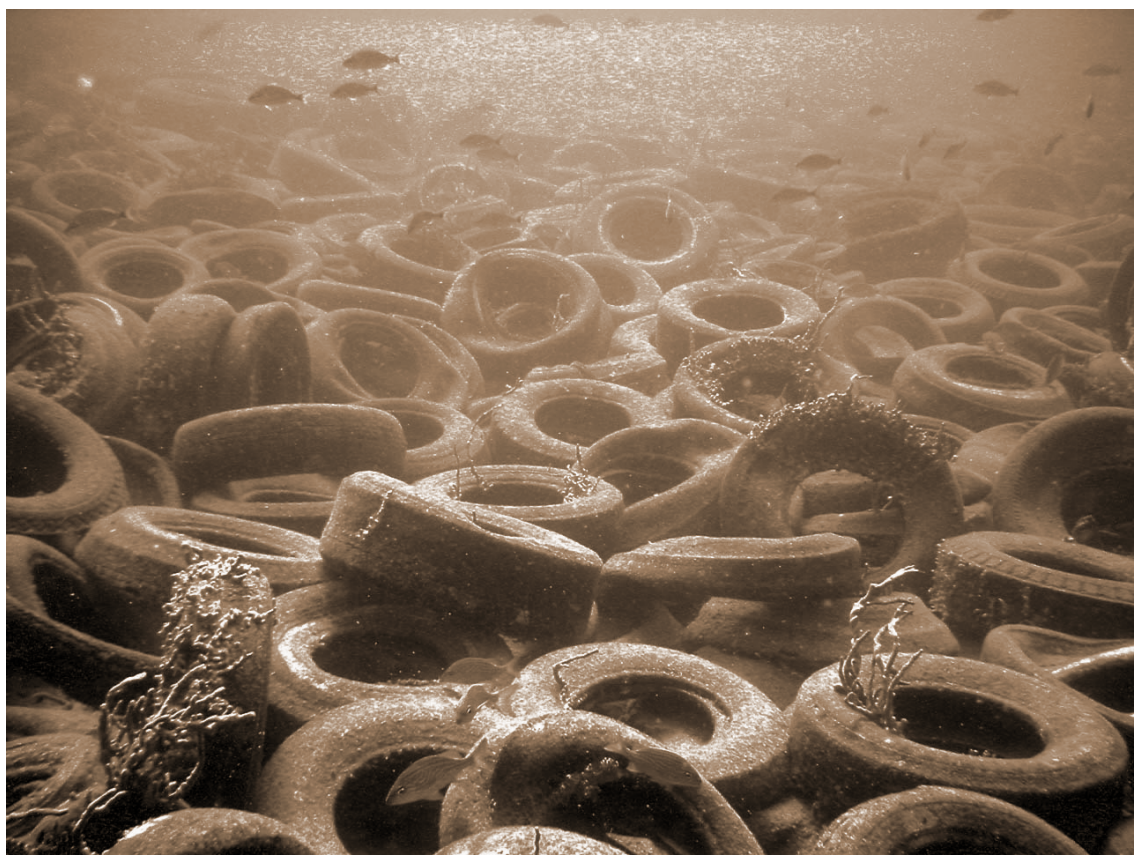

Figure 3: Tire field prior to clean-up, 2001. (Photograph courtesy of Matthew Hoelscher.)

The objectives of this project originally were to examine the feasibility of removing the tires piled up against the eastern edge of the reef as well as gain subjective insight into the impact of the tires on natural habitat.

\section{Methods}

During the summer of 2001 (June 6, 7, July 7, 8, 28, 29, August 25, 26, 2001) eight dive trips were accomplished. The purpose of the dives was to clear an area of the natural reef face of the tire incursions in an effort to determine possible large-scale clean-up methods that might be used to remove all of the remaining tires and give the natural reef the opportunity to recover.

Members of 10 groups participated in the initial clean-up project ( 86 divers total). The groups represented were: volunteer sport diving clubs, environmental groups, Nova Southeastern University Oceanographic Center students and staff, 
National Coral Reef Institute scientists, and Broward County Department of Planning and Environmental Protection staff.

Divers bundled 200 tires per dive on a total of 20 lift lines. After each two days of tire dives, commercial divers raised the bundles of tires using lift bags. Tire bundles were rafted together under 'pillow bags', and towed back to dock just inside Port Everglades inlet. The tires were removed from the water using a crane truck, rinsed of seawater and disposed of by a licensed tire recycler.

\section{Results and discussion}

Over the course of the eight dives 1600 tires were bundled, removed from the reef, brought ashore in Port Everglades, and recycled.

The western edge of the tire field abutted the eastern edge of a natural coral reef that ranges in depth from $15 \mathrm{~m}$ at the crest to $20 \mathrm{~m}$ at the edge of the eastern face. Photographs and diver surveys of one site indicate that areas of live coral that made up the hard substrate around this site have been severely damaged. At the removal site tires were found to be mostly clean of any substantial growth. Many of the tires were clean enough to read brand names (fig. 4). The area was covered with tires three to five deep with the deepest layer buried in sand. Tires that were substantially buried in the sandy substrate were left in place (fig. 5).

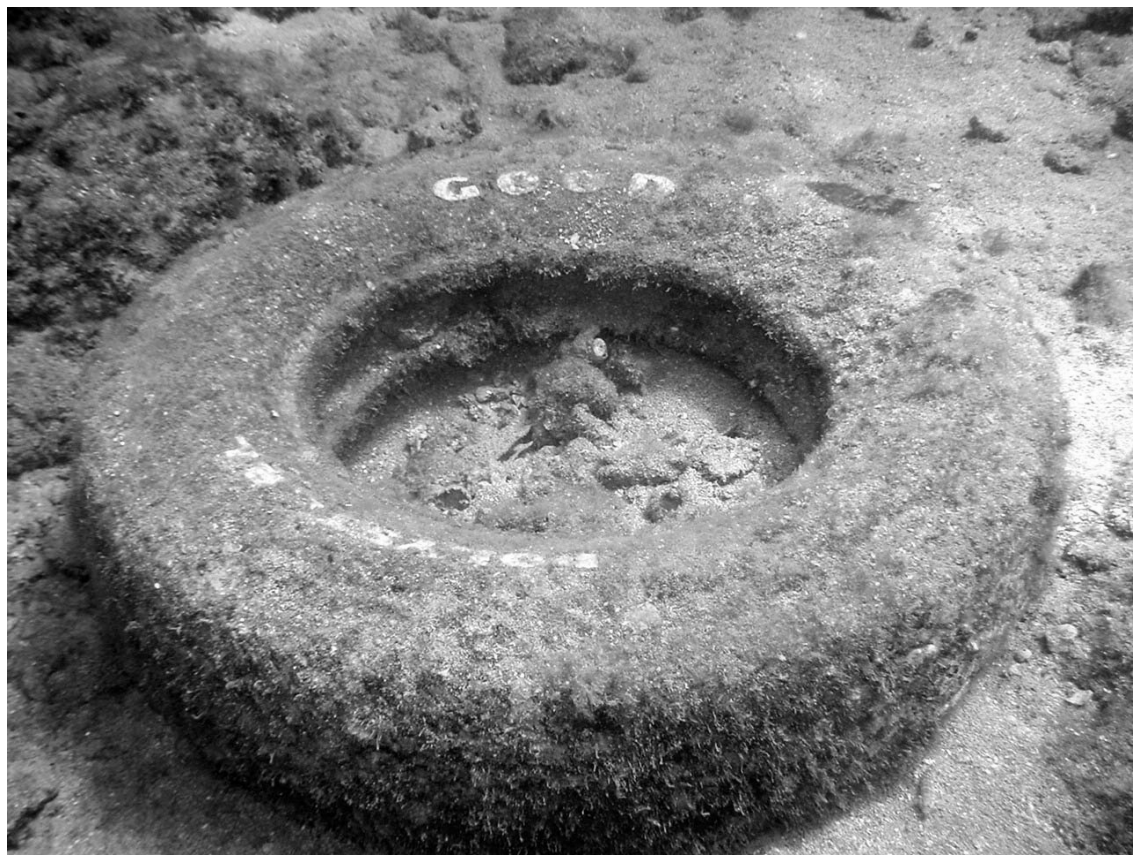

Figure 4: Tire showing original brand name and white wall. Photograph courtesy of Matthew Hoelscher. 


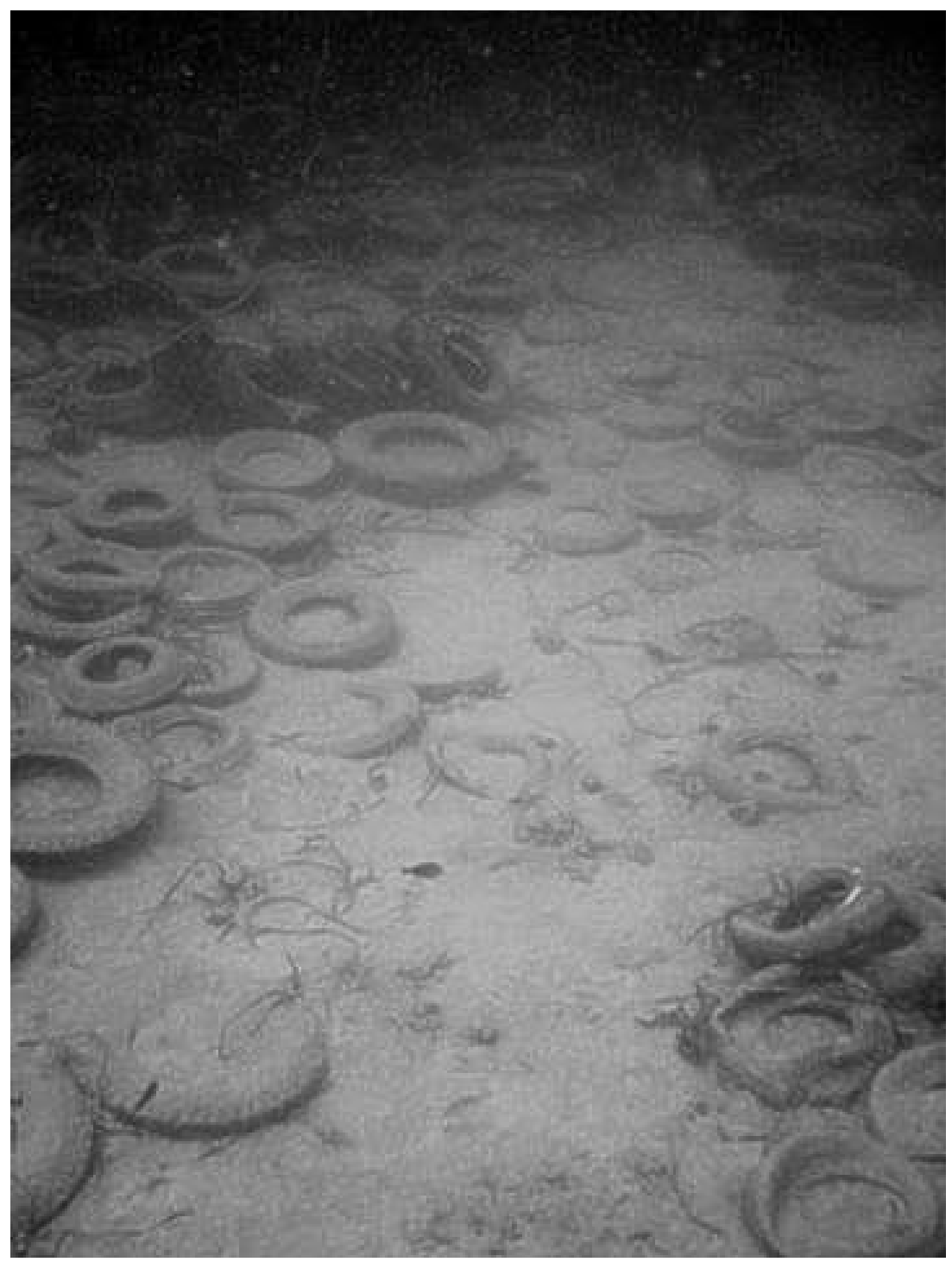

Figure 5: Photo of tires buried in sand, 2001. Photograph courtesy of Matthew Hoelscher.

During the course of the project an area approximately $20 \times 20$ meters was cleaned of loose tires. The western edge of the cleaned area was the fore reef slope and the cleaned site radiated out to the east. While clearing $250 \mathrm{~m}^{2}$ of tires from a $150,000 \mathrm{~m}^{2}$ site provides little restoration this project did bring a great 
deal of attention to the problem (e.g. community awareness through local dive organizations, newspaper and radio press coverage, and documentation for local environmental managers).

The project also contained a monitoring phase to track re-incursion of tires into the cleared area. Monitoring dives were planned quarterly for a year following the conclusion of the clean up. However, on the first monitoring dive conducted only two months following the cleanup it was determined that the entire site was already re-covered by tires. It is important to note that there had been no tropical storms or hurricanes during that time period. This highlights just how mobile the tires are due to nothing more than normal daily currents and wave action.

Recent studies conducted on the effectiveness of specific structures in enlarging and supporting a varied fish assemblage support the use of artificial reefs for this purpose $[5-10,12]$. However, these studies are based on the use of extremely stable, specially designed reef modules (fig. 6).

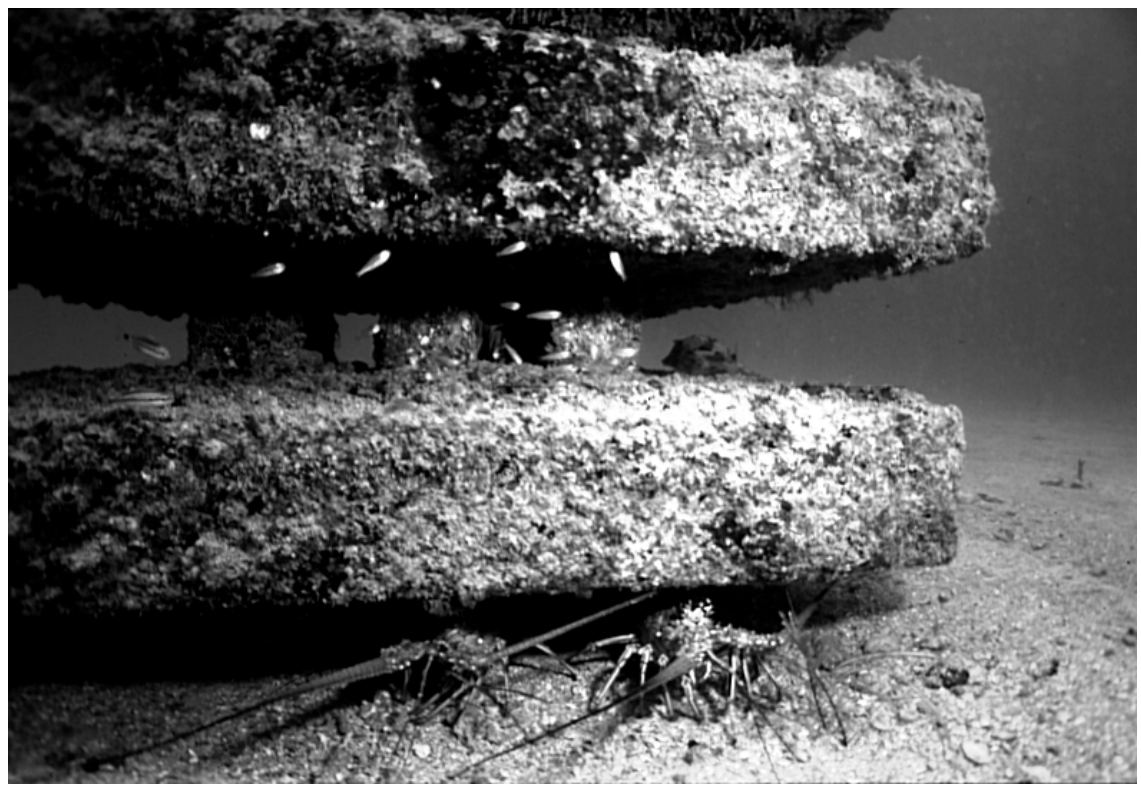

Figure 6: Example of a designed concrete artificial reef used for fish recruitment and predation studies [6].

The shortsighted use of unstable material to construct artificial reefs is an issue faced by many coastal areas [13]. Disposal of non-biodegradable solid waste in the name of artificial reef construction is a recipe for the type of environmental problem found on the reefs off southeast Florida. Movement of the tires has added to other natural and anthropogenic impacts (e.g. over-fishing, coastal construction, climate changes, water pollution, etc.) on the coral reef 
systems and the wildlife they support. However, while the issue of solid waste disposal has been examined and is generally prohibited as an inadvisable and improper use of the marine environment, problems created by decisions made in the past remain unresolved.

This leaves the question open as to how best to solve the problems created by past errors in judgment. The best possible solution, from an environmental perspective is a large scale removal project. Broward County and the State of Florida are encouraging a large-scale cleanup of the entire $150,000 \mathrm{~m}^{2}$ site. This will not be an easy task. The depth $(20 \mathrm{~m})$ and scale of the tire field and the continued movement of tires due to currents and wave action make it preferable, if not necessary to remove all the tires in a single clean-up. The cost of a project of this size may well be in the tens of millions of dollars. However, continued inaction will only allow additional physical damage to be done to the reefs which will in turn continue to impact wildlife living on the reefs and, in turn, the communities that benefit economically from use of the reefs.

In conclusion, despite excellent intentions, the creation of a tire reef to enhance fishing and recreational diving has instead created a major ecological problem and has highlighted the serious consequences of using unstable material in artificial reef construction.

\section{Acknowledgements}

The authors thank the National Oceanic and Atmospheric Administration (NOAA Award Number NA07FZ0950) for their financial support of this project as well as the many volunteer divers who participated in an effort to restore this delicate habitat.

\section{References}

[1] Bohnsack, J.A. \& Sutherland, D.L., Artificial reef research: a review with recommendations for future priorities. Bulletin of Marine Science 37, pp. 11-39, 1985.

[2] Bohnsack, J.A., Johnson D.L. \& Ambrose, R.F., Ecology of artificial reef habitats and fishes. IN: Seaman, W. Jr. and L.M. Sprague eds. Artificial habitats for marine and freshwater fisheries, Academic Press. San Diego, Ca. pp 61-107, 1991.

[3] Spieler, R.E., Gilliam, D.S. \& Sherman, R.L., Artificial substrate and coral reef restoration: what do we need to know to know what we need. Proceedings of the International Conference on Scientific Aspects of Coral Reef Assessment, Monitoring, and Restoration. Bulletin of Marine Science 69, pp.1013-1030, 2001.

[4] Carr, M.H. \& Hixon, M.A., Predation effects on early post-settlement survivorship of coral-reef fishes. Marine Ecology Progress Series 124, pp.31-42, 1995. 
[5] Eklund, A.M., The effects of post-settlement predation and resource limitation on reef fish assemblages. Doctoral dissertation, University of Miami, Coral Gables, Florida. 1996.

[6] Gilliam, D.S. Juvenile fish recruitment processes in south Florida: a multifactorial field experiment. Doctoral dissertation. Nova Southeastern University, Dania, FL. 1999.

[7] Sherman, R.L., D.S. Gilliam \& Spieler, R.E., A preliminary examination of depth associated spatial variation in fish assemblages on small artificial reefs. Journal Of Applied Ichthyology 15, pp.116-121, 1999.

[8] Sherman, R.L., Gilliam D.S. \& Spieler, R.E., Site dependent differences in artificial reef function: implications for coral reef restoration. Proceedings of the International Conference on Scientific Aspects of Coral Reef Assessment, Monitoring, and Restoration. Bulletin of Marine Science 69, pp.1053-1056, 2001

[9] Sherman, R.L., Gilliam, D.S. \& Spieler, R.E., Effects of refuge size and complexity on recruitment and fish assemblage formation on small artificial reefs. Proceedings of the $52^{\text {nd }}$ Annual Gulf and Caribbean Fisheries Institute Meeting, 1-5 Nov 1999, Key West, Florida, USA. pp. 455-467, 2001.

[10] Sherman, R.L., Gilliam, D.S. \& Spieler, R.E., Artificial reef design: void space, complexity and attractants. ICES Journal of Marine Science, 59, pp. S196-S200, 2002.

[11] McIntosh, G. Personal communication 2001. Pres. McIntosh Marine 1615 E. Camino Del Rio, Vero Beach, FL. 32963.

[12] Raymond B., Underwater photogrammetric survey of a tire reef. Proceedings of the Conference on Artificial Reefs, Florida Sea Grant. Daytona Beach, FL, 13 September. pp. 211-218, 1979.

[13] Grove, R.S., Sonu C.J. \& Nakamura, M., Design and engineering of manufactured habitats for fisheries enhancement, IN: Seaman, W. Jr. and L.M. Sprague eds. Artificial habitats for marine and freshwater fisheries. Academic Press. San Diego, Ca. pp 109-152, 1991.

[14] Duedall, I.W., Kester, D.R., Park P.K.\& Ketchum, B.H.., eds. Wastes in the Ocean. vol 4. John Wiley and Sons. New York. 818 pp, 1985. 